\title{
A IMPORTÂNCIA DO DIREITO DO TURISMO NOS CURSOS DO ENSINO SUPERIOR E PROFISSIONAL
}

\author{
THE IMPORTANCE OF TOURISM LAW IN ACADEMIC AND \\ VOCATIONAL COURSES \\ LA IMPORTANCIA DEL DERECHO DEL TURISMO EN LOS CURSOS \\ DE LA ENSEÑANZA SUPERIOR Y PROFESIONAL
}

Ana Branca Soeiro de Carvalho (anabrancacarvalho@gmail.com)*

João Carvalho Pina (joaocarvalhopina@gmail.com)**

\section{RESUMO}

No setor do turismo e, principalmente, nos cursos que formam os futuros profissionais desta área, as unidades curriculares de direito são consideradas importantes? É necessário ter a perceção da relevância dos diplomas jurídicos na atividade turística e como está prevista nos cursos de formação. O turismo é uma indústria global, que envolve viagens transfronteiras, comércio, transações e interações sociais, culturais e ambientais e apresenta o melhor em oportunidades e desafios para a regulamentação nacional e internacional (Atherton TC \& TA, 2003).

Este trabalho está dividido em duas partes: numa primeira, parte faz-se a análise de um quadro teórico; na segunda, a caracterização de programas escolares, de acordo com uma pesquisa exploratória. A pesquisa efetuada revelou a necessidade de se apresentar uma proposta para a implementação de um sistema de inovação do direito do turismo nas unidades curriculares e programas das escolas.

Analisaram-se vários cursos académicos e cursos vocacionais/profissionais que nos deram informação sobre a importância do direito do turismo nos programas escolares. Conseguimos obter uma amostra de 50 escolas, de um universo de 150, constantes dos sites das entidades públicas. Encontrámos nos diversos cursos académicos várias disciplinas básicas, consideradas muito importantes em matéria de direito.

O direito do turismo é muito eclético. Embora a lei seja a disciplina central, o nosso trabalho também analisa a importância do direito nas questões sociais, económicas, ambientais, de marketing, de planea- 
mento, de desenvolvimento e de gestão, envolvidas na regulamentação deste setor e a sua importância nos diversos cursos de formação.

Palavras-chave: Direito do turismo, programas de graduação, inovação, regulamentação, desenvolvimento

\section{ABSTRACT}

In the tourism sector and, especially, in the courses that form the future professionals of this area, the curricular units of law are considered important? It is necessary to have the perception of the relevance of the legal diplomas in the tourist activity and as foreseen in the training courses. Tourism is a global industry which routinely involves transboundary travel, trade, transactions and social, cultural and environmental interactions it presents the ultimate in opportunities and challenges for national and international regulation (Atherton TC\&TA,2003).

This paper is divided into two parts: theoretical framework and characterization of school programs, according to an exploratory research, through field research, and as final result, to present a proposal for funding and implementation of an innovation system of tourism law in school programs.

We analysed several academic courses and Vocational courses that give the best information about the importance of tourism law in school programs. A sample of 50 tourism Degree Programs from 150 schools, from institutional sites. We found in academic courses several core disciplines very important in law subject. Conclusions- Tourism Law is eclectic. While law is the core discipline, the subject also examines the social, economic, environmental, marketing, planning, development and management issues involved in regulating this industry and the importance for professional education.

Keywords: Tourism law, degree programs, innovation, regulation, development

\section{RESUMEN}

En el sector del turismo y, principalmente, en los grados que forman los futuros profesionales de esta área, las unidades curriculares de derecho se consideran importantes? Es necesario tener la percepción de la 
relevancia de los diplomas jurídicos en la actividad turística y como está prevista en los grados de formación. El turismo es una industria global que implica rutinariamente viajes transfronterizos, comercio, transacciones e interacciones sociales, culturales y ambientales, presenta lo mejor en oportunidades y desafíos para la regulación nacional e internacional (Atherton TC \& TA, 2003).

Este trabajo se divide en dos partes: el marco teórico y la caracterización de los programas escolares, de acuerdo con una investigación exploratoria, a través de la investigación de campo, y como resultado final, presentar una propuesta de financiación e implementación de un sistema de innovación del derecho del turismo en las asignaturas y programas de las escuelas.

Se analizaron varios grados académicos y cursos grados de formación profesional que dan la mejor información sobre la importancia de la ley de turismo en los programas escolares. Los 50 programas de grado de turismo de una población de 150 escuelas, presentes en las páginas web de entidades públicas. Encontramos en grados académicos varias asignaturas fundamentales muy importantes en materia de derecho.

La Ley de Turismo es ecléctica. Mientras que la ley sea la asignatura central, el tema también examina los aspectos sociales, económicos, ambientales, de marketing, de planificación, desarrollo y gestión involucrados en la regulación de esta industria y la importancia para la formación de activos.

Palabras clave: Derecho del turismo, programas de grado, innovación, regulación, desarrollo.

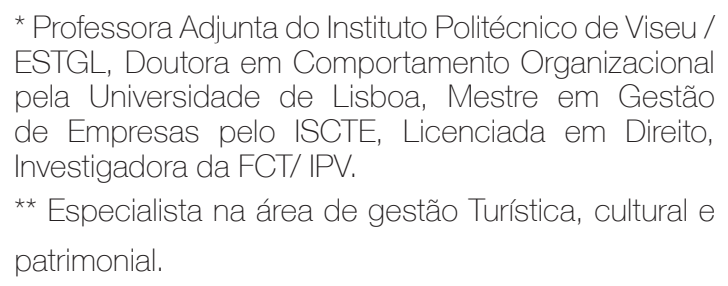

Submitted: 30th June 2017

Accepted: 30th January 2018 


\section{INTRODUÇÃO}

O turismo é uma indústria global que envolve, habitualmente, viagens transfronteiriças, comércio, transações e interações sociais, culturais e ambientais. Para além disso, apresenta o melhor em oportunidades e desafios para a regulamentação nacional e internacional (Atherton TC \& TA, 2003).

Neste paradigma do turismo sustentável devem tomar-se em consideração os atuais e futuros impactos económicos, sociais e ambientais, atendendo às necessidades dos visitantes, das empresas e trabalhadores do sector, do ambiente e das comunidades locais.

A atividade turística deve democratizar-se e humanizar-se, sendo, desta forma, acessível a todos e, simultaneamente, entendida como um direito, no sentido do Tourism for All. O turismo deve ser planeado e considerado como um sistema aberto e inter-relacionado com os subsistemas sociocultural, ambiental, económico e político-institucional.

Segundo Manuela Patrício (2017), durante muito tempo o método jurídico nada tinha a ver com a indústria do turismo. Contudo, quando se começou a dar ênfase à qualidade e à excelência do turismo, a chave para alcançar esses objetivos tornava indispensável a ordenação pública dos operadores turísticos, bem como dos bens e produtos turísticos. O direito impôs-se como uma ferramenta indispensável ao estudo e análise do setor turístico, pelo que se tornou necessário a introdução de uma cátedra de natureza jurídica nos planos curriculares dos vários cursos de turismo, que têm vindo a aparecer no panorama académico e profissional.

Ao contrário do que acontecia com a legislação turística, o direito do turismo tenta demonstrar a importância da regulação jurídica do setor turístico, através da análise da legislação reguladora deste setor, articulando-o com outras áreas de direito.

Há quem entenda que a legislação turística faz uma mera compilação de diplomas gerais e específicos, além de legislação conexa e trabalha, especificamente, alguns setores que considera relevantes (e.g. alojamento, restauração, gastronomia, viagens, etc.).

Atendendo a toda esta segmentação e dispersão legislativa, o direito do turismo pretende autonomizar-se do direito administrativo e criar um 
ramo específico do direito, por comparação ao direito da informática ou direito do ambiente. Diante do exposto, tem-se que o direito do turismo não pode ser classificado como de direito público ou de direito privado. Trata-se de ramo do direito que se situa entre essas duas esferas e deveria, como acontece em vários países, consubstanciar-se num código de turismo.

\section{A IMPORTÂNCIA DO DIREITO DO TURISMO}

A França foi o primeiro país do mundo a regular a atividade turística, vendo no turismo um meio de lazer e cultura (Py, 1996). Jegouzo (2016), enquanto docente na Université Panthéon Sorbonne (Paris I) Responsável pelo Departamento de Direito do Turismo, numa das suas intervenções, durante o processo de análise da Diretiva Comunitária UE) 2015/2302 do Parlamento Europeu e do Conselho, de 25 de Novembro de 2015, explicou que:

"O Código do Turismo francês é uma recolha organizada de textos legislativos e regulamentares aplicáveis em matéria de direito do turismo"

Na conferência internacional em 2017, sob a égide da Escola Superior de Hotelaria e Turismo do Estoril (ESHTE) e do Instituto Nacional para o Aproveitamento dos Tempos Livres (INATEL), focada nas normas (hard / soft law), associadas ao direito do turismo e turismo sustentável, reunindo, à semelhança de anos anteriores, vários especialistas nacionais e internacionais de direito do turismo, versando a temática da Sustainable Tourism Law, Carlos Torres (2017, p.238), mencionou que:

" a nova disciplina europeia das viagens organizadas e serviços de viagens conexos (Diretiva 2015/2302), também será objeto de alguma atenção, de acordo com estudos comparados com os autores do clássico Manuale di Diritto del Turismo, Vincenzo Franceschelli e Francesco Morandi".

O lazer e a cultura, considerados como direito fundamental para o ser humano, previsto na própria constituição da república portuguesa, enquadram a génese da atividade turística.

O direito do turismo surge como um ramo transcendental do direito, sendo heterogéneo, complexo e de extrema importância para o desenvolvimento sustentável da atividade turística, capaz de assegurar a 
harmonia das relações existentes na área de turismo.

Há um crescente reconhecimento, por parte da indústria, do governo e das agências internacionais, de que leis e instituições eficazes são fundamentais para alcançar resultados bem-sucedidos. Esses resultados serão, sem dúvida, a forma de tornar o setor do turismo sustentável, com criação de valor acrescentado e de maior qualidade. Os agentes e os intervenientes diretos e indiretos necessitam de uma maior eficácia e eficiência dos serviços, de forma garantir uma maior celeridade e segurança processual e procedimental, em termos de atividade turística.

As leis, específicas deste tipo de indústria, quando passaram para o labirinto de regulamentos locais, estaduais, regionais e internacionais, que agora a governam, obrigou a que se repensasse sobre o direito do turismo.

Os conceitos no turismo, como em qualquer outra área de atividade, são essenciais à sua cabal compreensão. O incorreto ou insuficiente domínio concetual não contribui para o conhecimento de uma atividade e, desconhecendo-se o objeto, não se afigura possível, de forma acertada, agir adequadamente sobre ele. Tal facto tem uma influência negativa na forma como são elaborados vários diplomas legais, criando permanentes alterações legislativas, que não favorecem o setor, criando diversos entendimentos e interpretações. No caso particular do turismo, pela sua juventude e complexidade, enquanto atividade económica, social e política, a incorreção é passível de redundar em prejuízo acrescido.

Considera-se, ainda, que intervêm na prossecução da política nacional de turismo as entidades públicas centrais, regionais e locais que, não tendo atribuições específicas na área do turismo, sejam responsáveis pela gestão e exploração de equipamentos e recursos turísticos. A Estratégia de Turismo 2027, pretende ser o referencial estratégico para o turismo em Portugal na próxima década, tendo por base um processo participativo, alargado e criativo com contributos de diversos ângulos da sociedade nas suas várias valências.

Consubstancia uma visão de longo prazo, combinada com uma ação no curto prazo, permitindo atuar com maior sentido estratégico no presente e enquadrar o futuro quadro comunitário de apoio 2021-2027. 


\subsection{DO DECRETO-LEI N. ${ }^{\circ} 191 / 2009$ DE 17 DE AGOSTO À ESTRATÉGICA TURISMO 2027}

O Decreto-Lei n. ${ }^{\circ}$ 191/2009 de 17 de agosto, que adotou uma lei de bases do turismo e consagra os princípios e o objetivo de uma política nacional de turismo, veio criar a nível nacional a base de orientação do direito do turismo, importante para que a legislação turística e o direito no turismo sejam unidades curriculares ministradas nos vários cursos superiores e cursos profissionais ligados a este setor.

Numa estrutura jurídica, uma Lei de Bases crê-se, e assim se tem, como constituindo o elemento "criador", a "fundação", a "expressão" de um desígnio estratégico, e o prenúncio de princípios e objetivos estratégicos, coletivamente assumidos, estruturante de um sector, que orientará, no futuro, o desenvolvimento de medidas de política.

A denominada Lei de Base das Políticas Públicas de Turismo - LBPPT, (Decreto-Lei no 191/2009, de 17 de Agosto), é a tradução normativa do programa do XVII Governo Constitucional na adoção de uma Lei de Bases do Turismo que consagra vários princípios orientadores.

Neste sentido, defende-se que uma Lei de Bases do Turismo deva prever os princípios gerais orientadores do desenvolvimento, competitividade e sustentabilidade do turismo. Do mesmo modo, podemos inferir que outros princípios que também são relevantes, e.g. os da rentabilidade e de articulação entre os diversos patamares do sistema turístico, não merecem qualquer referência no articulado do mencionado diploma.

Assim sendo, o diploma publicado, pese embora pretender definir a Lei de Bases do Turismo, não integra elementos fundamentais que, no seu teor, consagrem as bases das políticas de desenvolvimento sustentável e competitivo da atividade turística, no nosso país.

Podemos dizer, após análise do seu teor, que a LBPPT, por um lado, não identifica, clara e convictamente, o papel do turismo no modelo e processo de desenvolvimento do país e na sua economia; por outro não releva objetivamente a natureza e o âmbito dos papéis do Estado no desenvolvimento do nosso turismo.

Desta forma, resulta que a LBPPT embora referenciando nos art $\mathrm{s}$ $16^{\circ}, 17^{\circ}$ e $18^{\circ}$ os agentes públicos e os privados em termos de identificação, não é clara no que respeita à participação efetiva dos agentes que intervêm na cadeia de valor do turismo, o que se torna preocupante 
em termos de participação.

O art $17^{\circ}$ considera agentes públicos do turismo todas as entidades públicas centrais, regionais e locais com atribuições no planeamento, desenvolvimento e concretização das políticas de turismo, nomeadamente:

a) O membro do Governo responsável pela área do turismo;

b) A autoridade turística nacional;

c) As entidades regionais de turismo;

d) As direções regionais de economia;

e) As comissões de coordenação e desenvolvimento regional;

f) O Instituto da Conservação da Natureza e da Biodiversidade, Instituto Público ;

g) As regiões autónomas;

h) As autarquias locais.

Neste sentido o artigo $18 .^{\circ}$ indica quais são os fornecedores de produtos e serviços turísticos, englobando neste sentido: as pessoas singulares ou coletivas que exerçam uma atividade organizada para a produção, comercialização, intermediação e gestão de produtos e serviços que concorram para a formação de oferta turística nacional. Como se elenca no normativo:

a) Agências de viagens e turismo;

b) Empresas ou entidades exploradoras de empreendimentos turísticos;

c) Empresas de aluguer de veículos de passageiros sem condutor;

d) Empresas de animação turística e operadores marítimoturísticos;

e) Estabelecimentos de restauração e bebidas;

f) Empresas concessionárias de jogos de fortuna e azar;

g) Entidades prestadoras de serviços na área do turismo social;

h) Empresas de transporte aéreo, rodoviário, ferroviário e 


\section{Egitania}

s c i e $\Omega$ c i a

marítimo de passageiros e entidades gestoras das respetivas infra -estruturas de transporte.

Considera-se, ainda, que concorrem para a formação da oferta turística os estabelecimentos de alojamento local, as empresas organizadoras de eventos, congressos e conferências, bem como os agentes económicos que, operando noutros sectores de atividade, sejam responsáveis pela gestão e exploração de equipamentos e recursos turísticos. Como se pode ver este decreto-lei prevê no seu artigo $16 .^{\circ} n^{\circ} 1$ que em termos de

"conhecimento e investigação, cabe à autoridade turística nacional, em colaboração com as entidades regionais e locais do turismo, deve assegurar a coordenação de estudos, bem como o intercâmbio de informação relativa às atividades e aos empreendimentos turísticos, integrando entidades públicas ou privadas de investigação, formação e ensino na disponibilização, análise e divulgação dessa informação".

O presente decreto-lei, no seu art ${ }^{\circ}{ }^{\circ}$, estabelece as bases das políticas públicas de turismo, enquanto setor estratégico da economia nacional, e define os instrumentos para a respetiva execução. São princípios gerais das politicas públicas de turismo:

a) O princípio da sustentabilidade;

b) O princípio da transversalidade;

c) O princípio da competitividade.

$\mathrm{O} \operatorname{art}^{\circ} 7^{\circ}$, do referido diploma, prevê que:

" A Política Nacional de Turismo é prosseguida por um conjunto coerente de princípios e de normas reguladoras das atividades turísticas, da organização, atribuições e competências das entidades públicas, assim como do exercício das profissões que, por razões de segurança dos consumidores e qualidade do serviço, exijam tutela jurídica específica." Refere ainda qual deverá ser a missão destes agentes públicos do turismo, tentando criar como que uma estrutura de competências. Assim, promover o desenvolvimento da atividade turística através da coordenação e da integração das iniciativas públicas e privadas, de modo a atingir as metas do Plano Estratégico Nacional do Turismo, é um dos principais fins estatuídos (Quintas, 2011).

O turismo e as viagens são uma das maiores indústrias do mundo que crescem mais rapidamente. Segundo a AlECP (Agência para o Inves- 
timento e Comércio Externo de Portugal, E. P. E. (AlCEP, E. P. E. ou simplesmente AICEP)), no seu relatório de 2016, baseado nas informações do Banco de Portugal ( estatística da balança de pagamentos), o setor do turismo e viagens representou 45\% das exportações de serviços de Portugal.

Tendo em conta tudo isto, há necessidade de criar um quadro regulamentar que defina as grandes linhas de política do turismo e a forma como se irá proceder em termos de implementação na própria Europa. Nesse sentido, referimos a importância da Diretiva (UE) 2015/2302 do Parlamento Europeu e do Conselho, de 25 de Novembro de 2015, relativa às viagens organizadas e aos serviços de viagem conexos. $\bigcirc$ tradicional binómio bom funcionamento do mercado interno / elevado nível de defesa do consumidor surge como objetivo da nova diretiva (art. ${ }^{0}{ }^{1}$ ). As viagens, por definição, envolvem transações transfronteiriças sociais, culturais e comerciais que, sem dúvida, levantam mais desafios regulatórios para essa indústria do que talvez qualquer outra (Norel,2004). Há uma panóplia de áreas que têm relevância para o direito do turismo, como exemplo: turismo e marketing na saúde, F\&B, gestão de serviços de alimentação, gestão de marca, lei de viagem, viagens internacionais, gestão de hospitalidade e turismo, sustentabilidade em alojamento e turismo, gestão operacional, Corporate Finance e economia de viagens e turismo.

No entanto, há "recursos turísticos" que não tiveram tradução jurídica na LBPPT, enquanto conceito obrigatório e vinculativo de transposição para planos de ordenamento do território e urbanismo, no espaço litoral, de montanha ou meio rural, de forma a corresponder à natureza espacial e local do consumo da experiência turística, mantendo-se como um conceito económico e promocional sem relevância do ponto de vista físico e/ou territorial (Shaw et al, 2010).

É nosso objetivo caraterizar e compreender a importância estratégica da legislação turística ou do direito do turismo nos cursos de turismo.

Não obstante, não foi fácil perceber a diversidade de formação e de opção de conteúdos programáticos. Conforme constatámos, tal facto deve-se apenas a não existir uma uniformização ou harmonização na definição de conteúdos programáticos.

Pese embora toda esta problemática, o turismo oferece as melhores perspetivas de geração de emprego e desenvolvimento sustentável, 
particularmente nos países em desenvolvimento. A baixa formação/ educação de base de uma parte significativa do nosso empresariado, constitui um importante constrangimento a um desenvolvimento equilibrado do setor do turismo (e de outros setores, na medida em que esta característica não é, de modo nenhum, exclusiva dos empresários do turismo).

Numa das maiores pesquisas, online, da organização TBS (The Best Schools), conseguimos obter a informação de que um diploma de turismo permite que os alunos trabalhem em setores como operações de serviços de alimentação, agências de visitantes e convenções, negócios recreativos, agências de desenvolvimento turístico, hotéis, resorts, parques temáticos, serviços internacionais, agências de viagens e turismo, companhias aéreas e casinos.

De acordo com as estatísticas publicas e seguindo o mesmo sentido, o Bureau of Labor Statistics prevê -

" um crescimento do emprego de 44\% para os técnicos ou profissionais ligados ao planeamento de reuniões de hotéis, de 2010 até 2020 ".

Desta forma, pudemos verificar que a formação, mais generalizada em turismo, abrange duas estruturas autónomas:

a) os cursos profissionais (ministrados em escolas profissionais públicas e privadas);

b) as licenciaturas ( ministradas por politécnicos e universidades).

Em Portugal, o Turismo de Portugal, Instituto Publico, é o organismo público competente para "incentivar e desenvolver a política de formação de recursos humanos do turismo, e a respetiva investigação técnico - pedagógica, bem como coordenar, executar e reconhecer os cursos e as ações de formação profissional para essa área, além de certificar a aptidão profissional para o exercício das profissões turísticas" (art. ${ }^{\circ}$ 15. ${ }^{\circ}$, ali. d), Decreto-Lei n. ${ }^{\circ}$ 11/2014, de 22 de janeiro, da Lei Orgânica do Ministério da Economia).

No próprio site do Turismo de Portugal, Instituto Público é referido que: "a Qualificação de Recursos é um dos eixos estruturais do Plano Estratégico Nacional do Turismo (PENT). Neste sentido, o Turismo de Portugal aposta na formação de jovens e de profissionais do sector através da sua rede de Escolas de Hotelaria e Turismo, presentes ao longo do 
território nacional."

Pese embora vir referido o PENT, neste momento foi substituído por um outro instrumento estratégico. A construção de um referencial estratégico é determinante para o turismo em Portugal. Desta forma, pretendese criar duas dimensões de atuação:

a) Pensar estratégica e estruturalmente o turismo a 10 anos;

b) Agir no presente e no curto/médio prazo no Horizonte 2020.

A Estratégica Turismo 2027 é uma estratégia partilhada, de longo prazo, para o Turismo em Portugal, que visa:

a) Assegurar estabilidade nas grandes prioridades para o turismo nacional até 2027;

b) Promover uma integração das políticas setoriais;

c) Gerar uma contínua articulação entre os vários agentes do turismo;

d) Dar sentido estratégico às opções de investimento.

Paralelamente houve a criação dos LET ( Laboratórios Estratégicos para o Turismo).

Os LET são espaços de discussão que promovem a partilha de conhecimento, a identificação de áreas críticas e o desenho de soluções, bem como a delimitação de prioridades estratégicas, visando a obtenção de contributos para uma agenda a 10 anos para o turismo.

Têm como objetivo envolver, no plano regional, setorial e nacional, entidades institucionais e empresariais, públicas e privadas, associações de desenvolvimento regional e local, agentes de diplomacia económica, universidades e instituições internacionais.

A Resolução do Conselho de Ministros n. ${ }^{\circ}$ 134/2017 que aprova a Estratégia para o Turismo 2027, foi publicada em Diário da República, Série I de 27.09.2017.

De acordo com o diploma, o cariz multissetorial da atividade turística e as diferentes escalas territoriais de atuação do desenvolvimento turístico determinaram a importância de se construir uma estratégia concertada entre agentes públicos e privados.

Importa garantir que o turismo se afirme cada vez mais como uma ativi- 
dade sustentável ao longo do ano e ao longo do território, que valoriza os recursos naturais de que Portugal dispõe e que contribua para a criação de emprego e de riqueza para a promoção da coesão territorial e social.

\section{AS ESCOLAS DE TURISMO E AS UNIDADES CURRI- CULARES DE DIREITO}

Para cumprirem a missão prevista pelo Turismo de Portugal, I.P., foi criada, uma Rede Escolar. As escolas profissionais do turismo de Portugal são doze e encontram-se espalhadas por todo o continente: Coimbra, Douro-Lamego, Estoril, Faro, Lisboa, Oeste, Portalegre, Portimão, Porto, Setúbal, Viana do Castelo e Vila Real de Santo António.

No que concerne às licenciaturas, a formação pode ser feita em instituições públicas ou privadas de base politécnica ou universitária, como poderemos ver alguns exemplos mencionados, posteriormente.

Depois de efetuarmos a recolha das escolas, será necessário analisar as várias Unidades Curriculares (UC) constantes dos vários cursos de turismo no ensino superior e no ensino profissional.

São várias as nomenclaturas que podemos encontrar no ensino superior, como se pode ver nas páginas do próprio ministério, várias Unidades curriculares de direito (http://wnw.dgesc.gov.cv/):

\begin{tabular}{|l|}
\hline Direito do Turismo \\
\hline Direito de Viagens \\
\hline Direito do Turismo e Viagens \\
\hline $\begin{array}{l}\text { Direito do Turismo, planeamento e desen- } \\
\text { volvimento }\end{array}$ \\
\hline Legislação do Turismo \\
\hline $\begin{array}{l}\text { Direito e Políticas internacionais de turis- } \\
\text { mo }\end{array}$ \\
\hline Direito e Legislação do Turismo \\
\hline
\end{tabular}

No ensino profissional a área do direito aparece com mais especificida- 
des, criando uma maior abrangência em termos de conteúdos (http:// escolas.turismodeportugal. pt/activos-particulares):

\begin{tabular}{|l|}
\hline Direito Interno e Administração \\
\hline Direito das Agências de Viagem \\
\hline Direito dos Guias Turísticos \\
\hline Direito dos Operadores Turísticos \\
\hline Direito Hoteleiro, Direito do Alojamento \\
\hline $\begin{array}{l}\text { Direito Hoteleiro e dos Empreendimentos } \\
\text { Turísticos }\end{array}$ \\
\hline
\end{tabular}

Analisámos vários cursos de ensino superior e vários cursos vocacionais/profissionais para obtermos a informação de quais as UC lecionadas e a importância do direito do turismo nos programas escolares.

Para além das UC, supra mencionadas, verificámos a existência de outras áreas de direito, que podiam ser lecionadas, com um sentido estruturante ou de complementaridade:

a) Noções Fundamentais de Direito,

b) Direito Constitucional,

c) Direito Comercial,

d) Direito do Trabalho,

e) Direito Informático,

f) Direito Administrativo,

g) Direito Comunitário.

\section{METODOLOGIA E RESULTADOS}

A nossa pesquisa online, numa amostra de 50 escolas, num universo de aproximadamente 150 escolas públicas e privadas (valor obtido pela verificação das escolas existentes online), no ranking existente nos sites da DGES ( Direção Geral de Ensino Superior) e do Turismo de Portugal. Instituto Público, de entre outros cursos de Turismo do ensino superior, 
resultou de:

- 36 cursos de turismo (Gestão turística, Animação turística, Gestão Artística e Cultural, Gestão de Atividades Turísticas, Gestão da Restauração e Catering, Gestão do Turismo e da Hospitalidade, Gestão do Turística, Gestão Turística e Cultural, Gestão Turística e Hoteleira, Gestão Turística, Cultural e Patrimonial, Gestão de Empresas Turísticas, Turismo e Lazer);

-15 das escolas profissionais de turismo, dando primazia às reconhecidas pelo Turismo de Portugal, I.P.

Neste trabalho a questão de partida foi a seguinte:

- Nos cursos de turismo a formação o direito é considerada importante?

Em termos de metodologia, seguida nesta investigação, implicou:

a) numa fase inicial, uma investigação ou pesquisa de tipo exploratório, com recurso privilegiado à investigação

bibliográfica e documental, com as quais se pretende conhecer o campo teórico relacionado com os cursos de turismo e as áreas de direito que lhes são afins, sobretudo com duas áreas legislação turística e direito do turismo;

b) uma investigação ou pesquisa de tipo descritivo, orientada para conhecer, num estudo inicial, as caraterísticas e o contexto das UC nos vários cursos existentes.

Neste universo foram tidas em conta escolas públicas e privadas, que poderiam ministrar quer formação de ensino superior, quer formação de ensino profissional.

Como não existe nenhum estudo nesta área do direito do turismo, tivemos de recorrer aos dados existentes no site da Direção Geral de acesso ao Ensino Superior, no site do Turismo de Portugal. I.P. e na página oficial do Diário da República (DRE), tendo uma base de estudo documental, com fontes primárias.

Foi feita análise aos vários cursos profissionais reconhecidos e homologados pelo Turismo de Portugal, I.P. e ainda outros tantos nas universidades e politécnicos públicos e privados. 
Os métodos utilizados basearam-se na análise interpretativa da área de direito, que trabalha com conceitos opostos de ação/ reação (público/ privado; nacional/local; coletivo/individual), visando a génese dos equilibrios que funcionalizam a construção de um sistema legislativo e dos desequilibrios que podem perturbar tal funcionalidade.

Fazendo parte de um imenso leque de estruturas formativas, quer públicas, quer privadas, as instituições analisadas, foram as seguintes:

0170 - Universidade dos Açores - Faculdade de Economia e Gestão

0300 - Universidade de Aveiro

0604 - Universidade de Évora - Escola de Ciências Sociais

1202 - Universidade de Trás-os-Montes e Alto Douro - Escola de Ciências Humanas e Sociais

3023 - Instituto Politécnico de Beja - Escola Superior de Tecnologia e de Gestão

3045 - Instituto Politécnico de Bragança - Escola Superior de Comunicação, Administração e Turismo de Mirandela

3062 - Instituto Politécnico de Coimbra - Escola Superior de Educação de Coimbra

3105 - Instituto Politécnico de Leiria - Escola Superior de Turismo e Tecnologia do Mar

3121 - Instituto Politécnico de Portalegre - Escola Superior de Educação e Ciências Sociais

3163 - Instituto Politécnico de Viana do Castelo - Escola Superior de Tecnologia e Gestão

3182 - Instituto Politécnico de Viseu - Escola Superior de Tecnologia e Gestão de Viseu

3082 - Universidade do Algarve - Escola Superior de Gestão, Hotelaria e Turismo

3087 - Universidade do Algarve - Escola Superior de Gestão, Hotelaria e Turismo (Portimão)

4358 - Instituto Universitário da Maia

2223 - Universidade Católica Portuguesa - Faculdade de Filosofia e Ciências Sociais

4350 - Universidade Europeia

2400 - Universidade Lusíada

2800 - Universidade Lusófona de Humanidades e Tecnologias

2500 - Universidade Portucalense Infante D. Henrique

4115 - Escola Superior de Tecnologias de Fafe

4200 - Instituto Superior de Administração e Gestão 
4220 - Instituto Superior de Administração e Línguas

4270 - Instituto Superior de Ciências Educativas

4280 - Instituto Superior de Ciências Empresariais e do Turismo

4441 - Instituto Superior Politécnico Gaya - Escola Superior de

Desenvolvimento Social e Comunitário

4571 - ISLA - Instituto Politécnico de Gestão e Tecnologia - Escola Superior de Gestão

3162 - Instituto Politécnico de Viana do Castelo - Escola Superior de Educação

3031 - Instituto Politécnico do Cávado e do Ave - Escola Superior de Gestão

3139 - Instituto Politécnico do Porto - Escola Superior de Hotelaria e Turismo

4350 - Universidade Europeia

Recorremos aos planos curriculares existentes online, aos objetivos delineados por cada instituição/organização e às competências que os alunos devem adquirir através da formação (hard skills, soft skills e emotional skills), que em termos de competências preenchem o denominado CHA ( Conhecimentos, Habilidades e atitude).

Foi ainda feita uma análise documental com base na já referida LBPPT, selecionada pela importância que a mesma, enquanto Lei de Bases, representa no plano da hierarquia das fontes de direito, daí se extraindo conclusões quanto à capacidade de constituir um sistema e um modo institucional regulador do turismo, face às perspetivas sistémicas de enquadramento (quem, como, onde, quando, o quê, porquê e para quê).

Não podemos esquecer que o turismo é uma atividade económica da maior relevância no país e com tendência para o reforço do seu peso no PIB nacional. Desta forma, está na ordem do dia, uma tendência para a especialização regional da União Económica e Monetária e para a reforma da legislação e a sua harmonização em termos europeus.

É necessário justificar que este estudo incidiu, já que não há outros, na análise dos vários programas online e no levantamento das áreas de direito abordadas nos cursos de Turismo, quer nos de formação no ensino superior, quer nos formação profissional.

Tendo em conta este pressuposto, verificámos que nos vários cursos analisados, há necessidade de autonomizar o direito do turismo, não só como UC, mas também por se verificar a sua necessidade na formação de ativos. A UC de direito do turismo tem sido reconhecida como uma disciplina onde a qualidade e a exigência das boas práticas são 
as principais caraterísticas diferenciadoras, conforme se pode ver pelas informações justificativas dos planos de curso associados à formação. Como já foi anteriormente mencionado encontrámos, nestes cursos académicos, várias disciplinas básicas e comuns: Noções de Direito, Direito de Turismo, Legislação do Turismo, Direito de Turismo e Viagem, Direito de Planeamento e Desenvolvimento do Turismo (pós-graduação), Direito e Política de Turismo Internacional e também Direito das Agências de Viagem, Direito de Guias de Turismo, Direito de Operadores Turísticos, Direito de Hotéis, Direito de Hotelaria e Direito do Património.

Assim sendo, nos vários cursos associados ao turismo, os conteúdos programáticos da disciplina de Direito do Turismo / Legislação Turística, têm um objetivo geral e deverão proporcionar aos alunos a informação necessária à compreensão e análise da Legislação Turística Internacional e Nacional, identificar as principais organizações internacionais e nacionais com intervenção no setor do Turismo.

Nos vários programas analisados pudemos verificar que existe um conjunto de hard skills e soft skills fundamentais que nos surgem como objetivos na e para a formação:

- Evidenciar suficiente conhecimento teórico e aplicado sobre o conjunto de subtemas;

- Ser capaz de concretizar em aplicações reais os recursos teóricos adquiridos;

- Identificar as várias organizações internacionais e nacionais reguladoras do turismo;

- Compreender os vários diplomas legais;

- Ser capaz de atuar com concordância com a legalidade do setor;

- Ser capaz de obter os vários diplomas, dados e estatísticas relevantes para a atividade turísticas, tanto públicas como privadas e conhecer os principais diplomas legais que regem o turismo.

Outra área crucial do direito do turismo é o denominado direito internacional público e privado. Não podemos deixar de referir os vários parceiros internacionais, que promovem a investigação e o apoio à inovação científica e, sobretudo, influenciam o aparecimento de novos diplomas 
jurídicos e promovem a alteração de outros, com a finalidade de promover a cooperação e coesão social. Podemos mencionar, a título exemplificativo: - UN World Tourism Organization (UNWTO); World Travel and Tourism Council (WTTC); Organisation for Economic Co-Operation and Development (OECD); European Tourism Association (ETOA); European Cities Marketing (ECM); EURAIL.

Neste estudo, ficou claro que se torna relevante definir, nos vários cursos que ministram a unidade curricular de direito do turismo, a importância da legislação do turismo, clarificando e estruturando os seus objetivos (Dunford, 1990).

Para além disso, promover a autonomia do direito do turismo e direitos conexos, no sentido de clarificar a génese do mesmo e de forma transparente implementar as estratégias criadas, com base nos princípios do Código Mundial de Ética para o Turismo.

Neste sentido podemos elencar alguns desses objetivos, de forma a tornar mais percetível a importância deste ramo do direito:

a) Facultar conhecimentos especializados e atualizados nos domínios mais relevantes e economicamente significativos do direito público Económico e em especial do direito do turismo;

b) Preparar e atualizar o conhecimento do direito nacional e sensibilizar diretores hoteleiros e gestores e juristas especializados para as tendências de reforma do sector e da intervenção pública e reguladora do Estado;

c) Permitir um conhecimento adequado da principal legislação, doutrina e jurisprudência bem como do PENT e da Estratégia 2027, dotando os alunos de competências específicas que os habilitam a tomar decisões enquanto diretores hoteleiros e gestores ou juristas especializados;

d) Formar profissionais para o exercício de funções nos diversos sectores turísticos e da administração pública local, regional e nacional do turismo, na área da animação turística, operações e informação turística e consultoria em planeamento e gestão do território, privilegiando uma perspetiva de desenvolvimento regional e das atividades existentes.

Conforme analisado nos vários anúncios em revistas e jornais especializados, o Sol, praia, temperatura, golfe, turismo de natureza e rural, 
património e cultura, são fatores que atraem a Portugal cerca de 15 milhões de turistas cada ano.

Isto obriga a que Portugal tenha que se preparar para acolher mais e melhor, com produtos e serviços turísticos mais diversificados, diferenciados e sofisticados para os milhares de turistas, Portugueses e estrangeiros, que escolhem Portugal para seu destino de férias.

Neste cenário todos os profissionais do setor deverão possuir as competências e qualificações adequadas ao nível da Gestão, Técnicas e Práticas de Hotelaria e Turismo (Pereira, 2007).

Mas quais as principais preocupações verificadas?

Nos vários cursos, quer profissionais, quer de ensino superior, verificámos que há uma preocupação com o enquadramento jurídico das estruturas funcionais e de decisão estratégica, operacional e intermédia de e nas organizações públicas e privadas. $\bigcirc$ direito, pese embora ser relevante em todo o setor do turismo, tem sobretudo uma enorme incidência nos setores que passamos a mencionar:

- Alojamentos turísticos;

- Estabelecimentos de Restauração e Bebidas;

- Agências Viagens;

- Operadores Turísticos;

- Companhias Aéreas e outros transportes turísticos;

- Empresas de Animação Turística e organizadoras de atividades de lazer, de recreio e Organização e Gestão de Eventos;

- Quadros Técnicos Superiores de Departamentos de Turismo de Câmaras Municipais;

-Regiões de Turismo e Comissões de Coordenação e Desenvolvimento Regional;

- Assessoria e Auditorias técnicas em serviços turísticos;

- Ensino e formação profissional na área do Turismo.

Dando continuidade ao que temos analisado, podemos referir que, especificamente, os cursos profissionais de turismo têm como principal objetivo preparar jovens profissionais com competências técnicas na área dos serviços de informação, animação e organização de eventos 
em empresas de turismo, de reservas em agências de viagens e de receção e acolhimento em unidades turísticas.

Definem como saídas profissionais as seguintes:

-Técnico de Turismo/Rececionista de Turismo (Postos de Informação Turística);

-Guia de Museus e Monumentos;

-Técnico/Diretor de Agência de Viagens;

-Operador Turístico;

-Técnico de Empresas de Transportes Aéreos, Rodoviários e Marítimos;

-Técnico de Acolhimento em Unidades Turísticas;

-Promotor Comercial em Unidades Hoteleiras.

Com base na legislação associada aos profissionais de turismo, surge uma nova questão que terá de ser estudada para promover alterações curriculares e melhorar os programas curriculares - Será que as competências a adquirir e os objetivos das UC estão bem delineados para o futuro profissional do turismo?

Da análise efetuada, verificámos que o profissional da área de Hotelaria e Turismo é responsável por coordenar os serviços necessários para o bom funcionamento de hotéis, pousadas e resorts, pacotes de viagens, atividades de lazer e animação, entre outros. Além disto, cuida do planeamento, da divulgação e promoção de eventos e atividades de lazer (Costa, 1996).

Verificámos que faz parte do dia-a-dia de trabalho destes profissionais:

a) Contratar, orientar e supervisionar colaboradores;

b) Providenciar e organizar a infraestrutura e a logística para eventos;

c) Gerir viagens, exposições e congressos;

d) Administrar estabelecimentos turísticos;

e) Coordenar a acomodação, alimentação, segurança e transporte de participantes de eventos;

f) Programar as atividades nos resorts, hotéis e pousadas, levando 
em consideração sua localização, o potencial turístico da região e a infraestrutura do local;

g) Coordenar a preparação de refeições em hotéis e restaurantes;

h) Organizar eventos como feiras, congressos, exposições, convenções, etc.

Como análise de resultados, podemos inferir que há vários cursos profissionais reconhecidos e homologados pelo Turismo de Portugal, I.P. e ainda outros tantos nas universidades e politécnicos públicos e privados.

Nos vários cursos analisados é comum a ideia de que um bom profissional, da área de hotelaria e turismo, deve gostar de lidar com pessoas e coordenar equipes de trabalho. Nesse sentido, um profissional eficaz e eficiente deve estar consciente da regras e princípios que estão subjacentes à sua profissão, já que, conforme está previsto no art $6^{\circ}$ do Código Civil, "o desconhecimento da lei não isenta ninguém do seu cumprimento".

De entre outros resultados, também identificámos novas áreas de intervenção, que urge regulamentar, criando a ideia de existir um direito do turismo e não apenas legislação avulsa, sobre uma área tão relevante que é o turismo:

a) introdução à gestão turística ( ramos de direito para a estrutura do core business),

b) legislação turística e hoteleira ( vários tipos de alojamento e licenciamento - gestão de alojamento, food \& beverage e de equipamentos),

c) marketing de operações turísticas, técnicas de vendas e relacionamento com o cliente ( direito da informática e legislação sobre publicidade e promoção),

d) higiene e segurança pessoal e alimentar ( legislação e lei quadro),

e) noções de gestão contabilidade ( SNC),

f) legislação sobre património e cultura,

g) legislação fluvial ( cruzeiros e passeios). 


\section{CONCLUSÕES E CONSIDERAÇÕES FINAIS}

O turismo é atualmente um dos mais importantes setores da economia, seja pelos índices de crescimento que tem mantido ou pelos recursos humanos que mobiliza. Não contrariando essa tendência, em Portugal é também um dos setores económicos mais promissores, razão pela qual é imperativo formar recursos humanos capazes de responder com qualidade aos desafios atuais desta atividade.

O diferencial competitivo centra-se nas competências, a qualificação, capacitação e procura de novos potenciais. O capital humano e o capital intelectual, articulando com a inteligência emocional, devem promover a mudança de mentalidades e efetivar um maior dinamismo no turismo. Aliados às parcerias institucionais, nacionais e internacionais que permitem que os alunos das escolas sejam gestores de turismo de excelência, deve existir uma maior preocupação na forma como são ministrados os conteúdos programáticos visando uma investigação aplicada (Murphy, 1985), .

Com esta visão eminentemente prática, a maior parte dos cursos analisados, promove uma formação que é desenvolvida com base em casos práticos e atividades promovidos pelos formandos, privilegiandose metodologias pedagógicas que visam uma investigação /ação com base em modelos teóricos.

Podemos concluir que no geral pretendem colocar os formandos em contato direto com as questões das operações hoteleiras e/ou restauração do quotidiano profissional.

O volume de turistas em crescimento, a relevância económica, o efeito no desenvolvimento da economia, a elevada empregabilidade, a aposta neste setor importante para desenvolvimento, fazem do turismo uma das áreas de atividade com maior procura por empreendedores, empresas e profissionais.

Podemos concluir como Bernard Bouloc (2000) que o direito do turismo na União Européia está consolidado, graças ao programa plurianual a favor do turismo europeu, que seguindo as diretrizes estabelecidas pelo conselho europeu, incentivou não somente a atividade turística em si mas também a criação, por parte dos países membros, de um novo ramo de direito, que viesse a dar suporte legal ao Turismo e às áreas conexas a ele. 
O direito do turismo evidencia a necessidade de se autonomizar, deixando de ser um mero conjunto de legislação avulsa ou compilada, para passar a ter uma estrutura própria.

Nos vários cursos associados ao turismo, os conteúdos programáticos da disciplina de Direito do Turismo / Legislação Turística, têm um objetivo geral proporcionar aos alunos a informação/formação necessária à compreensão e análise da legislação turística internacional e nacional. Deverão, ainda, identificar as principais organizações internacionais e nacionais com intervenção no setor do turismo. Urge harmonizar o setor de formação em turismo, em termos jurídicos e em termos processuais, de forma a garantir uma maior certeza e segurança, ou em termos de gestão, uma maior eficiência e eficácia num turismo de qualidade. Os profissionais deverão ser possuidores de um cômputo de competências individuais e organizacionais, que Ihes permitam ter uma base identificadora.

Pese embora os vários cursos analisados terem como preocupação ministrar, na formação dos seus alunos, unidades curriculares de direito, não há, salvo raras exceções, uma linha condutora em termos de especificidades do direito em turismo. Importa salientar que, em matéria de responsabilidade objetiva, muito há a fazer tendo em conta a necessidade de formar os profissionais para uma realidade jurídica que está em mutação (Carvalho, 2017).

Este estudo teve limitações, já que apenas se conseguiram dados que deverão ser trabalhados em termos de proposta de inovação para a rentabilização das diversas áreas de turismo em termos jurídicos.

Não se conseguiu ir mais além de um intenso trabalho de recolha e análise.

Merece, num estudo posterior, a comparação dos objetivos, a análise das competência de cada unidade curricular e as saídas que cada curso promove. Uma articulação destes três fatores com as áreas de direito ministradas, poderá responder, de forma mais ampla, à questão do direito nos cursos de turismo.

Neste tipo de trabalho futuro, poderemos, ainda, elencar uma estrutura inovadora para a unidade curricular de Direito do Turismo. 


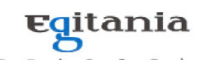

$s$ c i e $\Omega$ c i a

\section{BIBLIOGRAFIA}

Atherton Tc \& Ta, 2003, Tourism Travel And Hospitality Law Lbc Sydney, 534 Pages The New Millennium, Wilks J An Page S (Eds), Elsevier/Pergamon, London Bouloc, Bernard (Bouloc@Univ-Paris 1.Fr) Philoxenie: Programme Maxi-Annuel Pour Aider Le Tourisme Europeen. 14 Out. 2000, Paris.

Carvalho, Ab (2017) New Package Travel Directive, Edição Eshte| Inatel, Lisboa Costa, C. M. M. (1996), Towards The Improvementof The Efficiency And Effectiveness Of Tourism Planning And Development At The Regional Level: Planning, Organisations And Networks: The Case Of Portugal, University Of Surrey, Guidfor, London.

Dunford, M. (1990), Theories Of Regulation,Society And Space,8,297-321. London. Google Schollar, Link

Jegouzo, L (2009) Le Droit Du Tourisme : Un Droit En Gestation? Dalloz, Paris Jegouzo, L ( 2017 ) New Package Travel Directive, Edição Eshte| Inatel, Lisboa Murphy, P.E. (1985), "Tourism As A Community Industry-An Ecological Model Of Tourism Development", Tourism Management,4 (3), 180-193, Ny: Methuen. Google Scholar.

Norel, P. (2004), A Invenção Do Mercado, Instituto Piaget, Lisboa.

Patrício M.(2017) O Direito Do Turismo E O Alojamento Turístico, Livraria Almedina, Reimpressão Da $7^{a}$ Edição, Coimbra

Pereira, M. (2007), Introdução Ao Direito E Às Obrigações, Almedina, Coimbra. Py, P. (1996), Droit Du Tourisme,Dalloz, Paris

Quintas, P. (201 1), Legislação Turística, Almedina, Coimbra

Shaw, G., Williams, A. (2010), Tourism And Tourism Spaces, Sage, London.

Torres, C. (2017) New Package Travel Directive, Edição Eshte| Inatel, Lisboa 